ABDI: Jurnal Pengabdian dan Pemberdayaan Masyarakat ISSN: 2656-369X (Print), 2684-8570 (Online)

Volume 2 No. 1, Juni 2020

http://abdi.ppj.unp.ac.id/index.php/abdi

Email: abdi@ppj.unp.ac.id

DOI: https://doi.org/10.24036/abdi.v2il.35

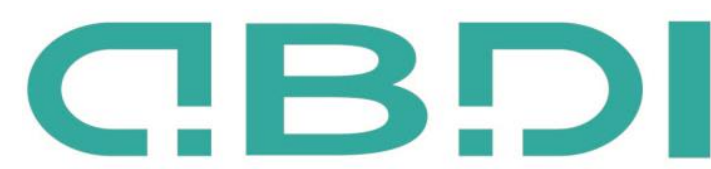

ABDI: JURNAL PENGABDIAN DAN PEMBERDAYAAN MASYARAKAT

\title{
Peningkatan Profesionalisme Guru Bahasa Indonesia di Kabupaten Musirawas Sumatera Selatan Melalui Pelatihan Menulis Artikel Jurnal Ilmiah
}

\author{
Susetyo Susetyo ${ }^{1}$, Rokhmat Basuki ${ }^{2}$, Noermanzah Noermanzah ${ }^{3}$. \\ 1,2,3 Magister Pendidikan Bahasa Indonesia, Universitas Bengkulu \\ E-mail: tsetyo@yahoo.com, rokhmatbasuki@gmail.com, noermanzah@unib.ac.id
}

\begin{abstract}
Abstrak
Tujuan kegiatan pengabdian ini dilakukan untuk: (1) membekali pengetahuan dan pemahaman Guru Bahasa Indonesia tentang menulis artikel jurnal ilmiah dan (2) membekali Guru Bahasa Indonesia agar terampil membuat artikel jurnal ilmiah yang sesuai dan dapat mempublikasi dalam dalam jurnal ilmiah ber-ISSN. Metode yang digunakan adalah sosialisasi dan pendampingan dalam menyusun artikel jurnal ilmiah. Materi yang disampaikan dalam sosialisasi adalah cara menulis artikel jurnal, yaitu hakikat, ragam artikel, sistematika artikel ilmiah, langkah-langkah menulis artikel, dan mempersiapkan artikel ilmiah yang siap dipublikasikan di artikel jurnal ilmiah nasional terakreditasi. Rancangan evaluasi untuk mengukur keberhasilan pelatihan adalah tes tertulis yang mencakup pengetahuan dan pemahaman tentang menulis artikel ilmiah meliputi hakikat artikel ilmiah, ragam artikel ilmiah, sistematika menulis artikel ilmiah, dan komponen artikel jurnal ilmiah. Kegiatan ini dilakukan mulai Mei sampai dengan November 2019 di Kabupaten Musi Rawas, Sumatera Selatan. Khalayak sasaran yang dilibatkan adalah guru-guru Bahasa Indonesia di Kabupaten Musi Rawas, Sumatera Selatan. Hasil capaian pengabdian menunjukkan bahwa pelatihan artikel jurnal ilmiah sangat bermanfaat bagi Guru Bahasa Indonesia Kabupaten Musi Rawas, mereka telah mengetahui dan memahami cara menulis artikel jurnal, dan mereka telah mampu menulis artikel jurnal ilmiah dengan baik. Kegiatan pegabdian perlu dilanjutkan dengan pendampingan yang lebih intensif agar mereka lebih mampu menulis arikel jurnal dan dapat dipuplikasikan pada jurnal ber-ISSN dan bahkan dapat dimuat di jurnal nasional terakreditasi.
\end{abstract}

Kata kunci: Artikel ilmiah, Peningkatan, Pendampingan, Profesionalme guru, Sosialisasi

\section{Abstract}

The purpose of this dedication activity is to: (1) equip the knowledge and understanding of Indonesian language teachers about writing scientific journal articles and (2) equip Indonesian language teachers to be skilled in making scientific journal articles that are appropriate and can be published in ISSN scientific journals. The method used is socialization and assistance in preparing scientific journal articles. The material presented in the socialization is how to write journal articles, namely nature, variety of articles, systematic scientific articles, steps to write articles, and prepare scientific articles that are ready to be published in accredited national scientific journal articles. The evaluation design to measure the success of the training is a written test that includes knowledge and understanding of writing scientific articles including the nature of scientific articles, various scientific articles, systematic writing of scientific articles, and components of scientific journal articles. This activity is carried out from May to November 2019 in Musi Rawas Regency, South Sumatra. The target audience involved was Indonesian language teachers in Musi Rawas Regency, South Sumatra. The results of the community service achievements show that the training of scientific journal articles is very beneficial for Indonesian language teachers in Musi Rawas district, they already know and understand how to write journal articles, and they have been able to write scientific journal articles well. Civil service activities need to be continued with more intensive assistance so that they are better able to write journal articles and can be applied to ISSN journals and can even be published in accredited national journals.

Keywords: Improvement, Mentoring, Teacher professionalism, Scientific articles, Socialization

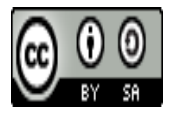

Received: 9 Desember 2019 Revised: 20 Januari $2020 \quad$ Available Online: 21 Januari 2020 


\section{Pendahuluan}

Pekerjaan guru merupakan pekerjaaan profesi. Profesi menunjuk kepada suatu pekerjaan yang menuntut keahlian, tanggung jawab, dan kesetiaan terhadap profesinya. Untuk itu, pekerjaan guru merupakan suatu pekerjaan tertentu yang menuntut persyaratan khusus dan istimewa sehingga meyakinkan dan memperoleh kepercayaan pihak yang memerlukan (Saud, 2009).

Sebagai suatu profesi, guru harus profesional dalam pekerjaannya. Guru yang profesional adalah guru yang memiliki keahlian, kemahiran, dan kecakapan yang memenuhi syarat mutu. Keseluruhan kepemilikan persyaratan tersebut digunakan untuk melaksanakan tugas pokok profesinya dengan baik, mendidik, mengajar, membimbing, mengarahkan, melatih, menilai, dan mengevaluasi peserta didik (Noermanzah, 2015). Guru yang profesional juga mampu melatih peserta didik untuk selalu berpikir kritis, kreatif, berkolaborasi, dan profesional (Noermanzah \& Friantary, 2019).

Guru yang profesional adalah guru yang menguasai keilmuan, termasuk struktur dan metode keilmuan serta menguasai penelitian terkait dengan bidang studinya (Suyatno \& Jihad, 2013). Penguasaan keilmuan tersebut akan bermakna apabila guru mau dan mampu mengembangkan serta mengiplementasikan profesionalitasnya dalam karya tulis ilmiah, baik berdasarkan gagasan, pengalaman, dan penelitian.

Pengiplementasian profesionalitas guru dalam karya tulis ilmiah, baik berdasarkan gagasan, pengalaman maupun penelitian menuntut guru untuk akrab dengan dunia tulis-menulis, terutama menulis karya ilmiah dalam bentuk artikel ilmiah. Untuk dapat mewujudkan hal tersebut guru dalam menulis artikel ilmiah perlu mendapat pengetahuan, pemahaman, dan keterampilan dari mitra kerja, yakni dengan para pakar dari perguruan tinggi, Musyawarah Guru Bidang Studi (MGMP), dan Dinas Pendidikan setempat. Dengan adanya pembekalan dan pendampingan tentang menulis artikel ilmiah kemampuan guru untuk mewujudkan tulisan artikel ilmiah yang baik akan terwujud.

Artikel ilmiah adalah suatu tulisan yang berisi tentang hasil dari kajian dan argumentasi ilmiah yang berhubungan dengan ilmu pengetahuan yang disajikan secara singkat dan jelas (Romli, dalam Kirom, 2019). Secara umum, struktur artikel ilmiah terdiri atas judul (head), nama penulis (by line), pendahuluan-lead (intro), bridging (penghubung antara intro dengan isi dalam bentuk identifikasi masalah atau pertanyaan), isis atau body (isi tulisan yang umumnya terdiri dari sub-sub judul), dan closing (penutup yang umumnya berisi simpulan, ajakan, atau pertanyaan tanpa jawaban). Artikel ilmiah biasanya terdiri atas judul, biodata penulis, abstrak, pendahuluan, metode penulisan atau metode penelitian, hasil dan pembahasan, simpulan, dan daftar pustaka. Selain itu, artikel ilmiah sebagai karya ilmiah juga memiliki ciri khas tersendiri, antara lain: (1) menyajikan fakta, (2) menyajikan definisi, (3) menguraikan permasalahan dengan cara jelas/lengkap, (4) menerapkan teori-teori secara spesifik, dan (5) disajikan permasalahan dengan cara deduksi atau berproses (Kusumaningrum, 2019). Untuk itu, dalam menulis artikel ilmiah, khususnya bagi Guru Bahasa Indonesia harus memiliki pemahaman secara khusus dan latihan secara berulang sehingga bisa menulis artikel ilmiah khususnya artikel ilmiah hasil penelitian.

Sampai saat ini secara keseluruhan guru tingkat SMP di Kabupaten Musi Rawas ada 658 (Kementerian Pendidikan dan Kebudayaan, 2019). Dari 658 guru yang golongan IV ada 117 selebihnya memiliki golongan di bawahnya. Jumlah Guru Bahasa Indonesia di SMP Kabupaten Musi Rawas berjumlah 150 (MGMP Bahasa Indonesia). Dari 150 Guru Bahasa Indonesia yang aktif di kegiatan MGMP ada 50 guru dan yang mengikuti kuliah S-2 Pendidikan Bahasa Indonesia di Program Magister Pendidikan Bahasa Indonesia FKIP Universitas Bengkulu ada 14. Keempat belas Guru Bahasa Indonesia yang mengikuti kuliah Program Magister Bahasa Indonesia pada umumnya belum dapat menulis artikel ilmiah dengan baik, hal ini ditunjukkan dari artikel ilmiah yang mereka buat untuk memenuhi tugas-tugas kuliah yang diberikan dosen.

Di samping itu, pangkat dan guru-guru di Kabupaten Musi Rawas masih banyak yang Golongan III, ini menunjukkan bahwa para guru belum banyak yang mampu untuk menulis karya ilmiah, termasuk artikel ilmiah yang dimuat di Jurnal dan Majalah Ilmiah. Hal lain juga ditunjukkan pada karya-karya tulis ilmiah Guru Bahasa Indonesia yang dimuat di jurnal atau majalah ilmiah, sebagian besar didominasi oleh para dosen, baik dosen-dosen Pendidikan Bahasa Indonesia di STKIP PGRI Lubuklinggau maupun dosen-dosen Program Sarjana dan Program Magister Pendidikan di Universitas Bengkulu. Selain itu, sebagian besar guru dalam kurang mampu menulis artikel ilmiah biasanya terletak 
pada penulisan tata bahasa dan teknik menulis yang prosedural (Blumner, dalam Musaffak \& Pangesti, 2018). Hal ini juga sesuai pendapat Ariningsih, dkk. (2012) apabila penulis melakukan kesalahan dalam penerapan ejaan, diksi, kalimat, maupun paragraf, hal tersebut akan mengganggu ketercapaian informasi antara penulis dengan pembaca. Bukan hanya itu, menulis artikel ilmiah hasil penelitian memiliki perbedaan dengan karya tulis lainnya, misalnya dalam artikel ilmiah hasil penelitian harus menunjukkan kebaruan hasil penelitian sehingga penulis harus memiliki referensi terbaru sesuai topik tulisannya. Referensi terbaru ini sebagian besar bisa kita dapatkan dari jurnal nasional dan internasioanal. Sebagian besar para guru belum bisa menuangkan gagasan kebaruan hasil penelitian ini sehingga keabanyakan artikel yang dibuat hanya berupa temuan penelitian sehingga belum bisa menunjukkan kebaruan atau karakteristik hasil penelitian.

Dari kenyataan di atas jelaslah bahwa kegiatan pengabdian kepada masyarakat dalam bentuk sosialisasi dan pendampingan tentang menulis artikel ilmiah bagi para Guru Bahasa Indonesia, baik guru SMP maupun SMA di Kabupaten Musi Rawas perlu dan mendesak dilakukan. Hal ini agar para guru Pendidikan Bahasa Indonesia memiliki kemampuan dan keterampilan dalam menulis artikel ilmiah yang benar dan baik serta dapat dipublikasikan.

\section{Metode Pelaksanaan}

Kegiatan pengabdian ini dilakukan dengan metode sosialisasi dan pendampingan. Sosialisasi (socialization) merupakan proses interaksi sosial dengan tujuan memperoleh pengetahuan, sikap, perilaku, nilai, dan beberapa keterampilan yang sangat penting sebagai makhluk sosial serta partisipan yang efektif dalam suatu masyarakat (Berns, dalam Farhatilwardah dkk., 2019). Sedangkan pendampingan merupakan proses memberikan bimbingan, arahan, dan masukan atau mereview yang dilakukan oleh narasumber kepada peserta secara langsung yang dilakukan secara bertahap untuk mencapai tujuan yang telah ditetapkan (Sumarsono \& Syamsudin, 2019). Sosialisasi penulisan artikel jurnal ilmiah disampaikan melalui ceramah, diskusi, dan agar mereka memahami cara menulis artikel jurnal ilmiah. Setelah memahami cara menulis artikel ilmiah, peserta diberi tugas untuk membuat artikel jurnal ilmiah dari hasil penelitian yang pernah dilakukan. Pendampingan kepada peserta pelatihan dilakukan dengan cara berdiskusi dan pengoreksian terhadap artikel ilmiah yang mereka buat. Pendampingan dilakukan beberapa kali sampai artikel ilmiah yang mereka buat siap untuk dipublikasikan. Khalayak sasaran pengabdian ini seluruh Guru Bahasa Indonesia di SMP dan SMA di Kabupaten Musi Rawas sebanyak 50 orang.

Kegiatan pengabdian ini bekerja sama dengan Pengurus MGMP Bahasa Indonesia di Kabupaten Musi Rawas Sumatera Selatan, Universitas Bengkulu, dan STKIP PGRI Lubuklinggau sebagai tempat penyelenggaraan pelatihan, sosialisasi, dan pendampingan penulisan artikel jurnal ilmiah. Evaluasi dilakukan setelah khalayak sasaran mendapatkan materi sosialisasi dan pendampingan penulisan artikel jurnal ilmiah. Hal ini dilakukan untuk mengukur pengetahuan dan pemahaman terhadap materi artikel ilmiah dan kemampuan menulis artikel jurnal ilmiah. Instrumen yang digunakan untuk mengukur pengetahuan dan pemahaman cara menulis artikel ilmiah yang melalui pertanyaan dalam bentuk tertulis yang mencakup hakikat artikel ilmiah, ragam tulisan artikel junal, sistematika menulis artikel ilmiah, dan komponen arikel jurnal berdasarkan hasil penelitian dan nonpenelitian atau hasil gagasan. Selanjutnya, evaluasi dilakukan terhadap karya peserta pelatihan yang berbentuk artikel jurnal ilmiah yang disusun untuk dilihat urutan penulisan (untuk artikel ilmiah berdasarkan penelitian: judul, abstrak dan kata kunci, pendahuluan, metode, hasil penelitian dan pembahasan, simpulan, daftar pustaka dan untuk artikel ilmiah berdasarkan hasil gagasan mencakup: judul, nama dan alamat penulis, abstrak dan kata kunci, pendahuluan, bagian inti, penutup, dan daftar pustaka dan substansi isi arikel ilmiah yang dibuat.

\section{Hasil dan Pembahasan}

\section{Kebermanfatan Penulisan Artikel Jurnal}

Angket kebermanfaatan terhadap pelatihan penulisan artikel jurnal yang disebarkan kepada peserta sosialisasi mencakup 12 butir pertanyaan mengenai pengetahuan dan pemahaman, berisi 
tentang: hakikat artikel jurnal, ragam artikel jurnal, komponen artikel jurnal, cara membuat judul artikel jurnal, cara menulis nama dan alamat penulis artikel jurnal, cara menulis abstrak dan kata kunci, cara menulis pendahuluan, cara menulis metode, cara menulis hasil dan pembahasan/inti, cara menulis simpulan dan saran, dan cara menulis daftar pustaka dalam artikel jurnal. Angket disusun dengan 4 (empat) pilihan, yaitu (1) sangat bermanfaat dengan skor 4, (2) bermanfaatan dengan skor 3, (3) kurang bermanfaat dengan skor 2, dan (4) tidak bermanfaat dengan skor 1. Dari 50 angket yang disebarkan kepada peserta pelatihan dan sosialisasi yang dikembalikan dan diisi oleh peserta pelatihan sebanyak 18. Hasilnya dapat dilihat pada tabel di bawah ini.

Tabel 1. Nilai Tingkat Kebermanfaatan Pelatihan Penulisan Artikel Jurnal Ilmiah

\begin{tabular}{|c|c|c|c|c|}
\hline No. & Nama & Nilai & \multicolumn{2}{|c|}{ Kriteria } \\
\hline 1 & $\mathrm{AL}$ & 44 & \multicolumn{2}{|c|}{ Sangat Bermanfaat } \\
\hline 2 & AR & 48 & \multicolumn{2}{|c|}{ Sangat Bermanfaat } \\
\hline 3 & EA & 48 & \multicolumn{2}{|c|}{ Sangat Bermanfaat } \\
\hline 4 & EI & 48 & \multicolumn{2}{|c|}{ Sangat Bermanfaat } \\
\hline 5 & FL & 48 & \multicolumn{2}{|c|}{ Sangat Bermanfaat } \\
\hline 6 & FAS & 48 & \multicolumn{2}{|c|}{ Sangat Bermanfaat } \\
\hline 7 & $\mathrm{KR}$ & 38 & \multicolumn{2}{|c|}{ Bermanfaat } \\
\hline 8 & KOM & 40 & \multicolumn{2}{|l|}{ Bermanfaat } \\
\hline 9 & $\mathrm{LF}$ & 40 & \multicolumn{2}{|l|}{ Bermanfaat } \\
\hline 10 & NW & 38 & \multicolumn{2}{|l|}{ Bermanfaat } \\
\hline 11 & ST & 42 & \multicolumn{2}{|c|}{ Sangat Bermanfaat } \\
\hline 12 & SM & 42 & \multicolumn{2}{|c|}{ Sangat Bermanfaat } \\
\hline 13 & SR & 38 & Bermanfaat & \\
\hline 14 & $\geqslant \mathrm{YR}$ & 38 & Bermanfaat & \\
\hline 15 & WS & 42 & \multicolumn{2}{|c|}{ Sangat Bermanfaat } \\
\hline 16 & MY & 44 & \multicolumn{2}{|c|}{ Sangat Bermanfaat } \\
\hline 17 & NK & 38 & \multicolumn{2}{|c|}{ Bermanfaat } \\
\hline 18 & RI & 42 & \multicolumn{2}{|c|}{ Sangat Bermanfaat } \\
\hline & Total & 766 & \multirow{2}{*}{\multicolumn{2}{|c|}{ Sangat Bermanfaat }} \\
\hline & ata-rata & 42,66 & & \\
\hline
\end{tabular}

Dari tabel di atas dapat dinyatakan bahwa secara keseluruhan pelatihan penulisan artikel jurnal sangat berhasil dengan nilai rata-rata 42, 66 termasuk ada dalamkategori sangat bermanfaat. Ada 11 atau $61,11 \%$ peserta pelatihan dalam angket yang menyatakan bahwa pelatihan penulisan artikel jurnal sangat bermanfaat dan 7 peserta pelatihan atau 38, $89 \%$ menyatakan bermanfaat. Dapat data di atas dapat disimpulkan bahwa pelatihan artikel jurnal ilmiah yang diberikan kepada Guru Bahasa Indonesia di Kabupaten Musi Rawas sangat berhasil. Peserta pelatihan telah memiliki pengetahuan dan pemahaman terhadap penulisan artikel jurnal ilmiah.

\section{Kemampuan Mempraktikkan Penulisan Artikel Jurnal Ilmiah}

Angkat terhadap kemampuan mempraktikkan penulisan artikel jurnal yang disebarkan kepada peserta sosialisasi mencakup 9 butir pertanyaan apakah mampu mempraktikkan penulisan artikel jurnal ilmiah dengan menulis judul artikel sistematika, nama dan alamat penulis, abstrak dan kata kunci, pendahuluan, metode penelitian, hasil penelitian dan pembahasan/isi, simpulan dan sana/penutup, dan daftar pustaka dengan 4 (empat) pilihan, yaitu (1) sangat mampu dengan skor 4, (2) mampu dengan skor 3, (3) kurang bermanfaat dengan skor 2, dan (4) tidak bermanfaat dengan skor 1. Dari 50 angket 
yang disebarkan kepada peserta pelatihan dan sosialisasi yang dikembalikan dan diisi angket sebanyak 18. Hasilnya dapat dilihat pada tabel di bawah ini.

Tabel 2. Nilai Tingkat Kemampuan Mempraktikkan Penulisan Artikel Jurnal Ilmiah

\begin{tabular}{cccc}
\hline No. & Nama & Nilai & Kriteria \\
\hline 1 & AL & 31 & Sangat Mampu \\
\hline 2 & AR & 30 & Mampu \\
\hline 3 & EA & 30 & Mampu \\
\hline 4 & EI & 30 & Mampu \\
\hline 5 & FL & 30 & Mampu \\
\hline 6 & FAS & 30 & Mampu \\
\hline 7 & KR & 27 & Mampu \\
\hline 8 & KOM & 27 & Mampu \\
\hline 9 & LF & 27 & Mampu \\
\hline 10 & NW & 27 & Mampu \\
\hline 11 & ST & 31 & Sangat Mampu \\
\hline 12 & SM & 31 & Sangat Mampu \\
\hline 13 & SR & 27 & Mampu \\
\hline 14 & YR & 27 & Mampu \\
\hline 15 & WS & 30 & Mampu \\
\hline 16 & MY & 27 & Mampu \\
\hline 17 & NK & 27 & Mampu \\
\hline 18 & RI & 30 & Mampu \\
\hline & Total & 519 & Mampu \\
\hline & Rata-rata & 28,83 & \\
\hline & & & Man \\
\hline
\end{tabular}

Berdasarkan hasil angket yang disebarkan kepada Guru-Guru Bahasa Indonesia Kabupaten Musi Rawas tentang mempraktikkan penulisan artikel jurnal ilmiah, ada 16,66 \% atau sebanyak 3 peserta menyatakan sangat mampu dan 83, $34 \%$ atau sebanyak 15 peserta menyatakan mampu. Artinya, pembekalan yang disampaikan pada waktu penyampaian materi kepada Guru-Guru Bahasa Indonesia Kabupaten Musi Rawas yang meliputi pengertian, artikel ilmiah, ciri-ciri artikel ilmiah, dan sistematika penulisan artikel telah dikuasai oleh peserta pelatihan artikel jurnal bagi Guru-Guru Bahasa Indonesia di Kabupaten Musi Rawas berhasil dengan baik atau mereka telah mengetahui dan memahami dengan baik materi pelatihan menulis artikel jurnal.

\section{Menulis Artikel Jurnal Ilmiah}

Dari 50 peserta yang ikut pelatihan penulisan artikel jurnal ilmiah hanya 18 peserta yang dapat menyelesaikan tugas menulis artikel jurnal ilmiah. Dari ke-18 artikel jurnal ilmiah yang disusun oleh peserta pelatihan penulisan artikel jurnal ilmiah diberi skor paling tinggi 100 dan paling rendah 20 . Hasil keseluruhan dapat dilihat pada tabel di bawah ini.

Tabel 3. Nilai Artikel Jurnal Ilmiah yang Disusun Peserta Pelatihan

\begin{tabular}{ccccccccccc}
\hline & \multicolumn{8}{c}{ Aspek yang Dinilai } & & \\
\cline { 3 - 9 } No. Nama & PJ & PAKK & PP & PM & PHP & PS & YR & Nilai & Kriteria \\
& & $(5)$ & $(10)$ & $(20)$ & $(10)$ & $(40)$ & $(10)$ & $(5)$ & & \\
\hline 1 & AL & 4 & 8 & 15 & 7 & 30 & 8 & 3 & 75 & Baik \\
\hline 2 & AR & 4 & 7 & 16 & 7 & 31 & 7 & 4 & 76 & Baik \\
\hline
\end{tabular}




\begin{tabular}{cllllllllll}
\hline 3 & EA & 4 & 8 & 14 & 8 & 29 & 8 & 4 & 75 & Baik \\
\hline 4 & EI & 4 & 7 & 13 & 9 & 33 & 8 & 4 & 78 & Baik \\
\hline 5 & FL & 4 & 8 & 15 & 8 & 30 & 8 & 4 & 77 & Baik \\
\hline 6 & FAS & 4 & 9 & 14 & 8 & 28 & 8 & 4 & 75 & Baik \\
\hline 7 & KR & 4 & 9 & 14 & 8 & 30 & 9 & 4 & 78 & Baik \\
\hline 8 & KOM & 4 & 9 & 14 & 8 & 29 & 8 & 4 & 75 & Baik \\
\hline 9 & LF & 4 & 8 & 14 & 8 & 32 & 7 & 4 & 77 & Baik \\
\hline 10 & NW & 4 & 8 & 15 & 9 & 35 & 8 & 3 & 82 & Baik \\
\hline 11 & ST & 4 & 9 & 11 & 8 & 30 & 9 & 4 & 75 & Baik \\
\hline 12 & SM & 4 & 9 & 14 & 8 & 29 & 8 & 4 & 76 & Baik \\
\hline 13 & SR & 4 & 9 & 14 & 8 & 30 & 9 & 4 & 78 & Baik \\
\hline 14 & YR & 4 & 9 & 14 & 8 & 28 & 8 & 4 & 75 & Baik \\
\hline 15 & WS & 4 & 7 & 13 & 9 & 33 & 8 & 4 & 78 & Baik \\
\hline 16 & MY & 4 & 8 & 15 & 8 & 30 & 8 & 4 & 77 & Baik \\
\hline 17 & NK & 4 & 8 & 15 & 9 & 35 & 8 & 3 & 82 & Baik \\
\hline 18 & RI & 4 & 9 & 11 & 8 & 30 & 9 & 4 & 75 & Baik \\
\hline Total & & & & & & & 1385 & \\
\hline \multicolumn{2}{r}{ Rerata } & & & & & & & 76,94 & Baik \\
\hline
\end{tabular}

Hasil artikel jurnal ilmiah yang dibuat 18 peserta pelatihan mencakup penulisan judul, abstrak dan kata kunci, pendahuluan, metode, hasil dan pembahasan, simpulan serta daftar pustaka sudah baik ataau dengan nilai rata-rata 77 atau termasuk dalam karegori baik. Kekurangan yang ada banyak adalah dalam penulisan abstrak, pendahuluan, hasil dan pembahasan, dan simpulan.

\section{Kesimpulan}

Beberapa kesimpulan dari kegiatan pengabdian kepada masyarakat ini, sebagai berikut:

a. Pelatihan menulis artikel jurnal ilmiah bagi Guru Bahasa Indonesia di Kabupaten Musi Rawas sangat berhasil. Hal ini ditunjukkan dari hasil angket yang menyatakan bahwa pelatihan menulis jurnal artikel ilmiah yang diperoleh sangat bermanfaat.

b. Dalam kemampuan mempraktikkan penulisan artikel jurnal semua menyatakan mampu mempraktikkan penulisan artikel jurnal ilmiah.

c. Hasil pelatihan berupa menulis artikel jurnal ilmiah yang disusun peserta pelatihan tergolong baik. Kelemahannya sebagian besar pada penulisan pendahuan, hasil penelitian dan pembahasan, dan penulisan abstrak dan kata kunci.

Berdasarkan capaian yang telah dilaksanakan dalam kegiatan sosialisasi dan pendampingan pelatihan tentang menulis artikel jurnal bagi Guru Bahasa Indonesia di Kabupaten Musi Rawas disarankan:

a. Perlu dilanjutkan lagi dengan pendampingan yang lebih intensif agar kemampuan Guru Bahasa Indonesia dalam menulis artikel jurnal ilmiah lebih baik dan artikel jurnal yang mereka susun dapat dimuat di jurnal ilmiah online ber-ISSN atau bahkan terakreditasi.

b. Jika memungkinkan agar peserta lebih paham dan mampu dalam menulis artikel jurnal ilmiah, peserta dilatih terlebih dahulu penelitian PTK yang benar sebelum mereka menyusun artikel jurnal ilmiah.

\section{Daftar Pustaka}

Ariningsih, N. E., Sumarwati, Saddhono, K. (2012). Analisis Kesalahan Bahasa Indonesia dalam Karangan Eksposisi Siswa Sekolah Menengah Atas. Basastra Jurnal Penelitian Bahasa, Sastra Indonesia dan Pengajarannya, 1(1): 48. 
Farhatilwardah, F., Hastuti, D., \& Krisnatuti, D. (2019). Karakter Sopan Santun Remaja: Pengaruh Metode Sosialisasi Orang Tua dan Kontrol Diri. Jurnal Ilmu Keluarga Dan Konsumen, 12(2), 115. doi:10.24156/jikk.2019.12.2.114

Kementerian Pendidikan dan Kebudayaan. (2019). Data Guru Semester Ganjil 2019/2020. https://dapo.dikdasmen.Kemdikbud.GO.ID/GURU/2/110600

Kirom, S. (2019). Peningkatan Kemampuan Menulis Artikel Ilmiah melalui Strategi Pembelajaran Berbasis Kecerdasan Verbal Linguistik. Silampari Bisa: Jurnal Penelitian Pendidikan Bahasa Indonesia, Daerah, dan Asing, 2(2), 208. doi:10.31540/silamparibisa.v2i2.616

Kusumaningrum, K. (2019). Publikasi dan Penulisan Artikel Jurnal Ilmiah Berdasarkan Gaya Selingkung. Makalah. Surakarta: Universitas Sebelas Maret Surakarta. doi:10.31227/osf.io/5gscx

Musaffak \& Pangesti, F. (2018). Penerapan Strategi Mind Mapping sebagai Upaya Peningkatan Kemampuan Mahasiswa dalam Menulis Artikel Ilmiah. Belajar Bahasa, 3(2). doi:10.32528/bb.v3i2.1589

Noermanzah, N. (2015). Peran Dosen Bahasa dan Sastra Indonesia dalam Mempertahankan Bahasa Indonesia sebagai Alat Pemersatu Negara Kesatuan Republik Indonesia pada Era Globalisasi. In Prosiding Seminar Nasional Bulan Bahasa 2015. Unit Penerbitan FKIP Universitas Bengkulu, p. 278. http://repository.unib.ac.id/11133/

Noermanzah \& Friantary, H. (2019). Development of Competency-Based Poetry Learning Materials for Class X High Schools. International Journal of Recent Technology and Engineering, 8(4), 6631.

Saud, U. S. (2019). Pengembangan Profesi Guru. Bandung: Alfabeta.

Sumarsono, A., \& Syamsudin. (2019). Peningkatan Kompetensi Penelitian Tindakan Kelas melalui Metode Pelatihan, Penerapan dan Pendampingan bagi Guru Sekolah Satu Atap Wasur di Kabupaten Merauke. Sarwahita, 16(02), 150. doi:10.21009/sarwahita.162.06

Suyatno \& Jihad, A. (2013). Menjadi Guru Profesional. Jakarta: Esensi.

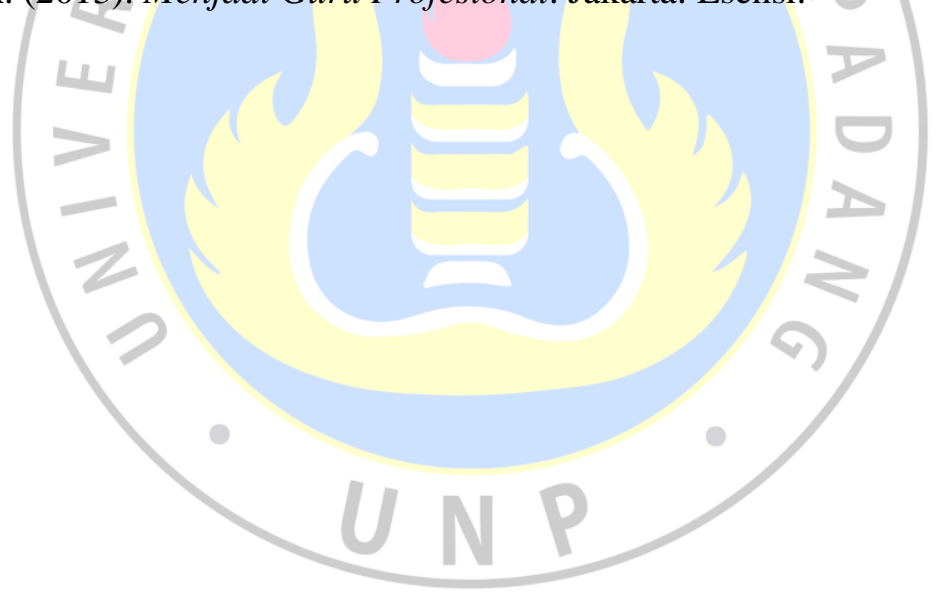

